\title{
The Dimensional Structure of the Self Report Psychopathy Scale
}

\author{
Rizal Abu Bakar ${ }^{1} \&$ Wan Nurul Izza Wan Husin ${ }^{2}$ \\ 1 Department of Psychology and Counselling, Faculty of Cognitive Science and Human Development, \\ University Malaysia Sarawak (UNIMAS), Sarawak, Malaysia \\ ${ }^{2}$ Department of Psychology and Counselling, Faculty of Human Development, Sultan Idris Education University, \\ Perak, Malaysia \\ Correspondence: Rizal Abu Bakar. Tel: 60-8258-4154.E-mail: abrizal@unimas.my
}

Received: July 4, $2018 \quad$ Accepted: July 16, $2018 \quad$ Online Published: November 29, 2018

doi:10.5539/ass.v14n12p184 URL: https://doi.org/10.5539/ass.v14n12p184

\begin{abstract}
Mental health issue is becoming increasingly prevalent in Malaysia. However, the country still lacks valid measures in assessing mental illness which includes psychopathy. The present study investigates the factorial structure of the Self Report Psychopathy Scale (SRPS). Specifically, it examines the feasibility of its use with Malaysian community. The SRPS was administered to a sample of undergraduate students. Result of principal components analysis yielded a four-factor solution. The obtained result was inconsistent with the proposed conceptual framework of this scale which captured only two factors (primary psychopathy and secondary psychopathy factors). The psychometric features of SRPS showed less support on its feasibility as a sound and reliable research instrument to measure students' psychopathic attributes in the Malaysian context. Other implications of the findings are discussed.
\end{abstract}

Keywords: mental illness, psychometrics, psychopathy, SRPS

\section{Introduction}

Psychopathy is known as a personality disorder that begins early in life and persists throughout the life span. This disorder was associated with shallow affect, callous disregard for others, and impulsive antisocial behavior (Korponay et al., 2017; Olanrewaju, Dominic, Julius, \& Funmilola, 2014). The documented literature revealed that psychopathy is closely related to juveniles (Gretton, Hare, \& Catchpole, 2004) as well as criminality and aggression in adults (Contreras-Rodríguez et al., 2015). Although most people believed that psychopathy necessarily implies criminal activity, Contreras-Rodriguez et al. (2015) and Savard, Lussier, Sabourin, and Brassard (2005) argued that psychopathic traits are well distributed in various segments of the general population. The current conceptualisation of psychopathy proposed two but interrelated facets that were correlated at .50 (Hare, 1991). The first of these facets, primary psychopathy is related to the emotional-interpersonal components emphasizing narcissism and social dominance (e.g., lack of remorse, entitlement, grandiosity, shallowness, low anxiety, manipulativeness and lying). Whereas, the second dimension, secondary psychopathy comprises traits and behaviours indicative of "social deviance" (juvenile delinquency, early behaviour problems, impulsiveness, aggressiveness, low tolerance to frustration, irresponsibility and antisocial behaviours) (Hare, 1991; Koenigs, Kruepke, Zeier, \& Newman, 2011; Levenson, Kiehl, \& Fitzpatrick, 1995).

Recent research in psychology and neuroscience revealed that psychopathy counts as a mental disease. The main reason is that psychopathy involves neural dysfunction that increases risk of serious harm and loss to people with psychopathy (Vincent, 2013). According to biomedical view, psychopathy can be considered as a mental illness. Blair, Mitchele and Blair (2005) argue that psychopaths do not fear punishment in a typical way, due to the hypoactivity in their amygdala. The failure of the amygdala to fulfil its function is enough to make psychopathy a dysfunction and a mental disease (Vincent, 2013). On a global scale, mental health problems continues to be high and affects many countries which include USA (Yamawaki, Riley, Sato, \& Omori, 2015), United Kingdom (Mental Health Foundation, 2016), Australia (Lawrence, Johnson, Hafekost, Haan, Sawyer, Ainley, Zubrick, 2015), Canada (Domene, \& Bedi, 2013), South Africa (Kleintjes, Lund, \& Swartz, 2013) and Japan (Yamawaki, Riley, Sato, \& Omori, 2015) to name a few. Arising from these issues, recent research tried to focus on management of mental health conditions (Vally \& Abrahams, 2016). Meanwhile, results of the National Health and Morbidity Survey conducted in Malaysia recently reported that mental illness is expected to be the second 
biggest health problem affecting Malaysians after heart diseases by 2020 (Institute for Public Health, 2015). A growing number of research was conducted to address this mental health issues in Malaysia such as studies on mental health development (Tsuey, Mohamad, \& Er, 2013), depression and anxiety (Minhat, Hamizah, \& Nor Afiah, 2015). The recent study in Malaysia showed that $28 \%$ of employees in a public university reported having probable mental health problems (Zuliza, Irniza, \& Emilia, 2017). Therefore, research on psychopathy is vital in order to tackle mental health issues.

Although the Psychopathy Checklist (PCL) (Cooke \& Michie, 2001) and its revision (PCL-R) are the most commonly used measures of psychopathy, it requires a lengthy interview, extensive training and access to file information related to official criminal records and institutional behaviour, which is not typically available in non-institutionalised populations. In short, PCL is highly used among incarcerated offenders (Cooke \& Michie, 2001; Harpur, Hare, \& Hakstian, 1989; Miller, Gaughan, \& Pryor, 2008). In response to these limitations, several self-report measures have been developed to assess psychopathy in non-institutionalised samples. According to Lilienfeld and Fowler (2006), there are several advantages (and disadvantages) of self-report psychopathy measures, including "economy," the elimination of concerns regarding inter-rater reliability and the ability (of some instruments) to assess for systematic response styles. The Self-Report Psychopathy Scale (SRPS) (Lecenson et al., 1995) is one of the self-report measures of psychopathy designed to assess psychopathic attributes in community samples. It consisted of two factors (primary and secondary psychopathy) named following Karpman's (1941) idea that there were two different types of individuals who exhibited similar behaviour but as a result of different etiologies. Levenson et al. (1995) postulated that primary psychopaths were believed to be born with a predisposition toward callousness, meanwhile secondary psychopaths engaged in bad behaviours as a result of environmental factors.

The purpose of this study is to examine the psychometrics properties of the SRPS. This research is important as researchers intend to assess the factorial structure and applicability of the SRPS in the Malaysian context. Several studies investigating the factorial structure of the SRPS have been conducted on several groups of sample such as Portugal (Barbosa, Gonçalves, Almeida, Ferreira-Santos, \& Marques-Teixeira, 2014), French-Canadian (Savard et al., 2005) and American (Lynam, Whiteside, \& Jones, 1999; Walters, Brinkley, Magaletta, \& Diamond, 2008) by utilizing factor analysis. The finding from these studies revealed that the SRPS retained a two-factor solution across Portugal, French-Canadian and American samples. Nonetheless, to date no documented literature has been found on the study of factorial structure of the SRPS in South East Asia, specifically, Malaysia. Cohen and Swerdlick (2005) assert that an additional validation study on a different population would help to verify the measure's utility beyond that of the inventory developers' setting.

Additionally, it is believed that replication of validation study is significant in that it could accumulate evidences to support the appropriateness, meaningfulness and usefulness of the specific inferences made based on the psychopathic attributes scores. The present study attempts to gather construct-related evidences particularly the factorial validity of an instrument (SRPS) as specified by the American Educational Research Association (AERA), American Psychological Association (APA) and National Council on Measurement in Education (NCME) (1999). According to AERA, APA and NCME (1999), such standards require the validation process of a measure to be on-going, with continuing efforts to establish the usefulness of the measure for specific populations and purposes.

Hence, the main focus of the present study was to examine the factor structure of the SRPS in the Malaysian context. To achieve this objective, two hypotheses were formulated. The first hypothesis suggested that the psychopathy construct consists of two factorial structures: (1) primary psychopathy [interpersonal and affective features]; (2) secondary psychopathy [impulsivity and a self-defeating lifestyle]. In addition, the second hypothesis hypothesized that the items of these two factors are reliable.

\section{Method}

\subsection{Participants}

In total, 342 undergraduate students $(n=342)$ participated in this study. The age of the respondents ranged from 18 to 26 years, with most of the respondents belonged to age group 21-23 years old. The respondents consisted of $33.3 \%$ male students $(n=114)$ and $66.7 \%$ female students $(n=228)$. The sample comprised of students from various ethnic groups, such as Malay ethnic (40.4\%), Chinese (35.4\%), natives of Sarawak (11.1\%), natives of Sabah (10.5\%) and Indian and other ethnics (2.7\%). Similarly, in terms of religious practices, the respondents came from different religious background such as Muslim (46.5\%), Christian and Buddhist shared similar proportion (22.5\% respectively), Catholic $(6.1 \%)$ and Hindu and others $(2.4 \%)$. The sample comprised of students from various faculties and level of studies. 


\subsection{Measures}

The participants responded to the Self-Report Psychopathy Scale (SRPS) (Levenson et al., 1995). This instrument is a self-report scale consisting of 26 questions that measure the primary and secondary psychopathy (Falkenbach, Poythress, Falki, \& Manchak, 2007). The items in the Levenson's Self-Report Psychopathy Scale are divided into two groups to represent both components of psychopathy.

There are sixteen items designed to measure interpersonal and affective features (primary psychopathy), which are items numbered 1, 2, 3, 4, 5, 6, 7, 8, 9, 10,11, 12, 13, 14, 15, and 16 (Falkenbach et al., 2007). On the other hand, there are ten items designed to measure impulsivity and a self-defeating lifestyle (secondary psychopathy), which are items numbered 17, 18, 19, 20, 21, 22, 23, 24, 25, and 26 (Miller et al., 2008). Each item was assessed on a 4-point Likert scale ranging from 1 (strongly disagree) to 4 (strongly agree).

This instrument was deemed reliable as the reliability coefficients were .85 for the total scale (Levenson et al., 1995). Meanwhile, the reliability estimates ranged from .82 to .83 for the primary psychopathy scale and from .63 to .69 for the secondary psychopathy scale (Brinkley, Schmitt, Smith, \& Newman, 2001; Levenson et al., 1995).

\subsection{Procedures}

The participants from one public university in Malaysia completed the original scale of the Self-Report Psychopathy Scale (SRPS) (Levenson et al., 1995) on a voluntary basis. Ethical permission was obtained prior to data collection and no reward or bonus points given to the participants. The data were analysed by using Statistical Package for Social Science (SPSS) software version 24.

\section{Results}

\subsection{Phase 1: Checking the Assumptions}

The data screening process yielded no violation of normality, linearity, multicollinearity and singularity assumptions. Preliminary analyses were also conducted to assess the suitability of the data for principal components analysis (PCA). Two main issues particularly the sample size requirement and the strength of the relationship among the items were investigated (Pallant, 2007; Tabachnick \& Fidell, 2007). Following Tabachnick and Fidell's (2007) suggestion, a minimum ratio of 5 to 1 ; that is 5 cases for each item to be factor analysed. As the data for this study consisted of 342 cases $(n=342)$ and 26 items, it fulfilled the sample size criterion.

A few outputs which measure inter-correlation and factorability of the items were also examined: These outputs included: (1) correlation coefficients matrix, (2) Kaiser-Meyer-Olkin (KMO) measure of sampling adequacy and (3) Bartlett's test of sphericity. Findings revealed that the strength of the inter-correlations among the items was satisfactory as most of the correlation coefficients were greater than .30 (Tabachnick \& Fidell, 2007). Meanwhile, the Kaiser-Meyer-Olkin (KMO) measure of sampling and the Bartlett 's test of sphericity also satisfied the assumption of the appropriateness of factor analysis as Bartlett 's test was significant $(p<.05)$ and the KMO index was .741.

As the Bartlett test reached significant level, it indicated that the correlation matrix has significant correlations among at least some of the items (Hair, Tatham, \& Anderson, 2010). Similarly, the KMO index of larger than .60 indicated that the data reached the minimum value for a good factor analysis (Hair et al., 2010). In light of these preliminary analyses, results revealed that the study data were suitable for the factor analysis.

\subsection{Phase 2: Defining Factors and Assessing Overall Fit}

Principal components analysis (PCA) with orthogonal rotation (varimax) was performed to derive factors and assess overall fit. Although, it was known that there were two factors that underlie this construct, this exploratory approach (varimax) was intended to get an empirical idea regarding the maximum number of factors (Field, 2005; Tabachnick, \& Fidell, 2007). A few methods were used to assist in the decision concerning the number of factors to extract: (1) Kaiser's latent root criterion, (2) a priori criterion, and (3) scree test criterion.

Kaiser's rule is the most commonly used technique in factors extraction, and this rule recommends that only factors with eigenvalues greater than 1 are considered significant and retained for further analysis (Hair et al., 2010). Based on the output generated, it revealed that the construct of psychopathy had a 4-factor solution as there were 4 components that had an eigenvalue greater than 1 and these 4 components accounted for $37.16 \%$ of the total variance explained.

A priori criterion is a reasonable criterion if the researcher already knew number of factors to extract before conducting factor analysis (Hair et al., 2010). As the researchers attempted to replicate other researchers' work, it 
was hypothesized that this analysis would extract a 2-factor solution as grounded by the scale developers' conceptual framework on psychopathy.

Further, visual inspection of the scree plot was done to investigate the number of possible structures. The scree test result indicated that 4 was the maximum number of factors to extract as there were 4 points above the elbow; the point at which the curve changes direction and becomes horizontal (Hair et al., 2010; Pallant, 2007).

Based on the results obtained from Kaiser's latent root criterion and scree test criterion there were 4 possible factors to retain. Nonetheless, the priori criterion showed that there this construct was made up of only 2 possible factors. To this end, the researchers chose to retain 4 factors, as the 4-factor solution had greater variance explained and the scree plot clearly showed that these data yielded 4 dimensions. The decision to retain a 5 -factor solution was deemed reasonable as the researchers strove to have the most representative and parsimonious set of factors possible (Hair et al., 2010; Pallant, 2007). Furthermore, Hair et al. (2010) assert that in choosing the number of factors, parsimony is important and any decisions on the appropriateness of a factor solution are best guided by conceptual bases and meaningfulness of the grouping factors.

Finally, in deciding the final factor solution, the (rotated) factor loadings significance for each item was scrutinised in determining that item's contribution for a particular structure (Field, 2005; Hair et al., 2010). Only factor loadings with a value greater than .4 were retained, as it met the minimum level for the interpretation of structure (Stevens, 1992). An investigation of the factors loading showed that 22 items loaded significantly on a particular factor, while another 4 items (items no. 11, 13, 17 and 26) had no significant loading on any factor. Meanwhile, an examination of communalities also showed that item number 18 was weak as its communalities was less than $.3(.212)$.

\subsection{Phase 3: Interpreting the Factors and Respecifying the Factor Model}

In the stage of refining the factor model, items number 11, 13, 17 and 26 were removed for further analysis as their factor loadings were not significant. Item number 18 was also removed, due to its poor communalities. The analysis was repeated again using oblique rotation (direct oblimin) and extracting a 4-factor solution.

After respecifiying the factor model, the results from 21 items showed that the structure improved considerably. There were four components with eigenvalues exceeding 1 , and the 4 -factor solution accounted for $42.65 \%$ of the variance. All the items fitted well with the other items in its component as all the communalities were greater than .3 (Pallant, 2007).

The pattern matrix for PCA with oblimin rotation of a 4-factor solution of the Psychopathy items are presented in Table 1. The results from the pattern matrix contains information about the unique contribution of an item to a factor (Field, 2005: Hair et al., 2010; Tabachnick \& Fidell, 2007).

The first factor explained $17.20 \%$ of the variance in psychopathy. There were nine items loaded on this factor: items number $1,2,3,4,5,6,7,8$, and 9. The values of loading estimate were ranging from .452 to .668 . As the content of these items reflected 'self-interest' elements, this factor was named as 'self-interest' factor. An example of item for this behaviour was "Looking out for myself is my top priority."

The second factor included 5 items with loadings exceeding . 50 and accounted for $10.59 \%$ of the variance. The five items were items number: $10,12,14,15$, and 16. The loading estimates were ranging from .502 to .723 . These items clearly refer to the "manipulative behaviours" factor. A typical example of item was "I make a point of trying not to hurt others in my pursuit of my goals". Thus, the second component was termed as "manipulative behaviours' factor.

Four items loaded highly $(.465-.728)$ on the third factor and this factor accounted for $8.08 \%$ of the variance. Items numbered 19, 20, 21 and 23 formed this factor and captured the 'behavioural control' elements. Therefore, this factor was named as 'behavioural control'. A sample item for this behaviour was "I quickly lose interest in tasks I start."

The fourth factor consisted of three items with loading exceeding $.50(.506-.788)$ and explained $6.79 \%$ of the variance. The three items consisted of items number 22, 24 and 25 of psychopathy inventory. These items mapped into the fourth factor and this factor was called as "emotional control". An example of item for this emotional control was "When I get frustrated, I often "let off steam" by blowing my top". 
Table 1. Oblique Rotation of Components Analysis Factor Matrix

\begin{tabular}{|c|c|c|c|c|c|}
\hline \multirow{2}{*}{ Description of the item } & \multicolumn{4}{|c|}{ Factor loadings } & \multirow{2}{*}{ Communality } \\
\hline & 1 & 2 & 3 & 4 & \\
\hline 5- Making a lot of money is my most important goal. & .668 & & & & .431 \\
\hline $\begin{array}{l}\text { 6- I let others worry about higher values; my main concern is with the bottom } \\
\text { line. }\end{array}$ & .642 & & & & .439 \\
\hline $\begin{array}{l}\text { 1- Success is based on survival of the fittest; I am not concerned about the } \\
\text { losers. }\end{array}$ & .587 & & & & .369 \\
\hline 4- My main purpose in life is getting as many goodies as I can. & .554 & & & & .332 \\
\hline 2- For me, what's right is whatever I can get away with. & .525 & & & & .355 \\
\hline $\begin{array}{l}\text { 3- In today's world, I feel justified in doing anything I can get away with to } \\
\text { succeed. }\end{array}$ & .512 & & & & .413 \\
\hline 7- People who are stupid enough to get ripped off usually deserve it. & .499 & & & & .321 \\
\hline 8- Looking out for myself is my top priority. & .465 & & & & .384 \\
\hline $\begin{array}{l}\text { 9- Tell other people what they want to hear so that they will do what I want } \\
\text { them to. }\end{array}$ & .452 & & & & .307 \\
\hline 16- Cheating is not justified because it is unfair to others. & & .723 & & & .537 \\
\hline $\begin{array}{l}\text { 14- I feel bad if my words or actions cause someone else to feel emotional } \\
\text { pain. }\end{array}$ & & .698 & & & .479 \\
\hline 12- I make a point of trying not to hurt others in my pursuit of my goals. & & .64 & & & .449 \\
\hline 15- Even if I were trying very hard to sell something. I wouldn't lie about it. & & .632 & & & .421 \\
\hline 10- I would be upset if my success came at someone else's expense. & & .502 & & & .315 \\
\hline 20- I don't plan anything very far in advance. & & & .728 & & .574 \\
\hline 21- I quickly lose interest in tasks I start. & & & .626 & & .457 \\
\hline 19- I find that I am able to pursue one goal for a long time. & & & .594 & & .395 \\
\hline 23- Before I do anything, I carefully consider the possible consequences. & & & .465 & & .394 \\
\hline 25- When I get frustrated, I often "let off steam" by blowing my top. & & & & -.788 & .635 \\
\hline 24- I have been in a lot of shouting matches with other people. & & & & -.786 & .611 \\
\hline $\begin{array}{l}\text { 22- Most of my problems are due to the fact that other people just don't } \\
\text { understand me. }\end{array}$ & & & & -.506 & .339 \\
\hline
\end{tabular}

Note. * Factor loadings less than .40 have not been included and items have been sorted by loadings on each factor

\subsection{Phase 4: Reliability Analysis}

The reliability test was conducted based on the final 4-factor solution result that consists of 21 items relating to psychopathic attributes. The reliability coefficient result revealed that one of the items (item numbered 10) was not reliable and inconsistent with other items. Therefore, these two items were removed and reliability analysis was conducted again. The final result of reliability coefficients for each factor are presented in Table 2 . The alpha coefficients for the first, second and fourth factor were satisfactory as the value for each subscale was reaching .70 (ranging from .600 to .731) indicating that the newly formed subscales were internally consistent (Pallant 2007; Field, 2005). The alpha coefficient for the third factor was less reliable (Cronbach's alpha $=.545$ ). The reliability of the whole scale was also satisfactory as the value was higher than $.70($ Cronbach's alpha $=.741)$ (Pallant 2007; Field, 2005).

Table 2. Reliability analysis of the 4-factor solution for the SRPS

\begin{tabular}{cccl}
\hline Factor & $\begin{array}{c}\text { Cronbach's } \\
\text { alpha }\end{array}$ & $\begin{array}{c}\text { N of } \\
\text { items }\end{array}$ & \multicolumn{1}{c}{ Sample item } \\
\hline Self interest & .731 & 9 & Looking out for myself is my top priority \\
Manipulative behaviours & .683 & 5 & I make a point of trying not to hurt others in my pursuit of my goals \\
Behavioural control & .545 & 4 & I quickly lose interest in tasks I start \\
Emotional control & .600 & 3 & When I get frustrated, I often "let off steam" by blowing my top \\
\hline
\end{tabular}

Note. The reliability of the whole scale is .741 . 


\section{Discussion}

The dimensional structure obtained in this investigation documents that the SRPS is a multidimensional scale tapping into various dimensions of psychopathic attributes. Although the original scale developed by Levenson et al. (1995) was intended to measure two factors of psychopathy, this study found four prominent factors of SRPS; self-interest, manipulative behaviours, behavioural control and emotional control. However, further examination of the items and their respective factors showed that items in the first and second factors (self-interest and manipulative behaviours) tapped onto Primary Psychopathy domain, meanwhile items in the third and fourth factors (behavioural control and emotional control) tapped onto Secondary Psychopathy domain, The self-interest and manipulative behaviours factors (first and second factors) consist of items which indicated emotional-interpersonal tendencies focusing on narcissism and social dominance such as manipulativeness, lack of remorse, grandiosity, entitlement, shallowness, and low anxiety. Whereas the behavioural control and emotional control (third and fourth factors) consist of items which reflected social deviance such as impulsiveness, anxiety, irresponsibility, aggressiveness, low tolerance to frustration and antisocial behaviours.

The validity and reliability of the SRPS may not be deemed satisfactory as these four-factor solution accounted for only $37.16 \%$ of the variance of psychopathy attributes. Most of the statisticians agreed that a good instrument should explain more than $50 \%$ of the variance of the measured construct (Hair et al., 2010). Furthermore, only the first factor (self-interest) exhibited acceptable internal reliability (Cronbach's alpha $=.731$ ). The reliability coefficient of the third factor (behavioural control) was only .545. The lower alpha for the third and fourth factors were quite consistent with previous studies of SRPS as the researchers observed that the reliability of the secondary psychopathy factor was lower than those of the primary psychopathy factor as found in Hicklin and Widiger (2005) ( $\alpha=$.66), Lynam et al. (1999) ( $\alpha=$.68), Miller, Lynam, Widiger, and Leukefeld (2001) $(\alpha=.63)$, and Ross, Lutz, \& Bailley (2004) $(\alpha=.62)$. Meanwhile, seven of the items were removed due to low loading estimates. It was not unexpected to remove these unreliable items as previous validation study conducted by Savard et al. (2005) revealed that they have removed twelve items of SRPS in their factor analytic study. Another study conducted by Brinkley et al. (2001) also revealed that several items in the SRPS did not perform well for their targeted samples. However, Savard et al. (2005) and Brinkley et al. (2001) did not further elaborate the reasons of removing these weak items.

\section{Conclusion}

In conclusion, the findings of this study did not provide consistent support to the two-factor structure of psychopathic attributes as measured by the Levenson's Self-Reported Psychopathy scale in the Malaysian context. It is worthy to note that previous validation studies which supported the two-factor structure of the SRPS were conducted in Western countries samples such as Portugal (Barbosa et al., 2014), French-Canadian (Savard et al., 2005) and American (Lynam et al., 1999; Walters et al., 2008). Studies by Brinkley et al. (2001) also suggested that the two-factor structure of SRPS may be different for Caucasians and African-Americans and, as such, it was presumed that the SRPS may not perform the same way in different ethnic and racial populations. Taking these limitations into consideration, however, the SRPS still has several potential benefits for and psychologists and researchers. It is inexpensive, quick and easy to administer. It may also be a useful screening instrument for selecting samples in certain studies, given how costly and time consuming it is to do full interviews with all shortlisted samples. Therefore, this study calls upon the development of psychopathy attributes instrument which is suitable for eastern countries community particularly Malaysia. The new instrument should be best suited for both populations; clinical and non-clinical settings to cross-validate its utilities. The new instrument also could be better to discriminate between high and low scores on the psychopathic attributes.

\section{References}

American Educational Research Association, American Psychological Association, National Council on Measurement in Education, Joint Committee on Standards for Educational, \& Psychological Testing (US). (1999). Standards for educational and psychological testing. Amer Educational Research Assn.

Barbosa, F., Gonçalves, S., Almeida, P. R., Ferreira-Santos, F., \& Marques-Teixeira, J. (2014). The Levenson Self-Report Psychopathy Scale (LSRPS): translation and adaptation to European Portuguese (LabReport No. 7). Porto: Laboratory of Neuropsychophysiology (University of Porto) 2014. Retrieved from: http://www.fpce.up.pt/labpsi/data_files/09labreports/LabReport_7.pdf

Blair, J., Mitchell, D., \& Blair, K. (2005). The psychopath: Emotion and the brain. Blackwell Publishing.

Brinkley, C. A., Schmitt, W. A., Smith, S. S., \& Newman, J. P. (2001). Construct validation of a self-report 
psychopathy scale: does Levenson's self-report psychopathy scale measure the same constructs as Hare's psychopathy checklist-revised? Personality and Individual Differences, 31(7), 1021-1038.

Cohen, R. J., \& Swerdlik, M. E. (2005). Psychological testing and assessment: An introduction to tests and measurement. Boston: McGraw-Hill.

Contreras-Rodríguez, O., Pujol, J., Batalla, I., Harrison, B. J., Soriano-Mas, C., Deus, J., \& Pifarré, J. (2015). Functional connectivity bias in the prefrontal cortex of psychopaths. Biological Psychiatry, 78(9), 647-655.

Cooke, D. J., \& Michie, C. (2001). Refining the construct of psychopathy: Towards a hierarchical model. Psychological assessment, 13(2), 71-88.

Domene, J.D., \& Bedi, R. P. (2013). Counseling and psychotherapy in Canada: Diversity and growth. In R. Moodley, U. P. Gielen, \& R. Wu (Eds.), Handbook for counseling and psychotherapy in an international context (pp. 106-116). New York: Routledge.

Falkenbach, D., Poythress, N., Falki, M., \& Manchak, S. (2007). Reliability and validity of two self-report measures of psychopathy. Assessment, 14(4), 341-350.

Field, A. (2005). Discovering statistics using SPSS. London: Sage Publications.

Gretton, H. M., Hare, R. D., \& Catchpole, R. E. (2004). Psychopathy and offending from adolescence to adulthood: a 10-year follow-up. Journal of consulting and clinical psychology, 72(4), 636-645.

Hair, J. F., Tatham, R. L., \& Anderson, R. E. (2010). Multivariate Data Analysis. London: Prentice Hall.

Hare, R. D. (1991). The Hare Psychopathy Checklist-Revised. Toronto, Ontario: Multi-Health Systems

Harpur, T. J., Hare, R. D., \& Hakstian, A. R. (1989). Two-factor conceptualization of psychopathy: Construct validity and assessment implications. Psychological Assessment: A Journal of consulting and clinical Psychology, 1(1), 6-17.

Hicklin, J., \& Widiger, T. A. (2005). Similarities and differences among antisocial and psychopathic self-report inventories from the perspective of general personality functioning. European Journal of Personality, 19, 325-342.

Institute for Public Health (IPH). (2015). National Health and Morbidity Survey 2015: Volume II. Non-Communicable Diseases, Risk Factors \& Other Health Problems, Ministry of Health Malaysia.

Karpman, B. (1941). On the need of separating psychopathy into two distinct clinical types: the symptomatic and the idiopathic. Journal of Criminal Psychopathology, 3, 112-137.

Kleintjes, S., Lund, C., \& Swartz, L. (2013). Barriers to the participation of people with psychosocial disability in mental health policy development in South Africa: a qualitative study of perspectives of policy makers, professionals, religious leaders and academics. BMC International Health and Human Rights, 13(1), 17.

Koenigs, M., Kruepke, M., Zeier, J., \& Newman, J. P. (2011). Utilitarian moral judgment in psychopathy. Social cognitive and affective neuroscience, 7(6), 708-714.

Korponay, C., Pujara, M., Deming, P., Philippi, C., Decety, J., Kosson, D. S., \& Koenigs, M. (2017). Impulsive-antisocial psychopathic traits linked to increased volume and functional connectivity within prefrontal cortex. Social cognitive and affective neuroscience, 12(7), 1169-1178.

Lawrence, D., Johnson, S., Hafekost, J., Boterhoven, De, Haan, K., Sawyer, M., Ainley, J., \& Zubrick, S. R. (2015). The Mental Health of Children and Adolescents. Report on the second Australian Child and Adolescent Survey of Mental Health and Wellbeing. Department of Health, Canberra.

Levenson, M. R., Kiehl, K. A., \& Fitzpatrick, C. M. (1995). Assessing psychopathic attributes in a noninstitutionalized population. Journal of personality and social psychology, 68(1), 151-158.

Lilienfeld, S. O., Fowler, K. A., \& Patrick, C. (2006). The self-report assessment of psychopathy: Problems, pitfalls, and promises. In C. J. Patrick (Ed.), Handbook of psychopathy (pp. 107-132). New York, Guilford.

Lynam, D. R., Whiteside, S., \& Jones, S. (1999). Self-reported psychopathy: A validation study. Journal of personality assessment, 73(1), 110-132.

Mental Health Foundation. (2016). Fundamental Facts About Mental Health 2016. Mental Health Foundation: London.

Miller, J. D., Gaughan, E. T., \& Pryor, L. R. (2008). The Levenson Self-Report Psychopathy Scale: An examination of the personality traits and disorders associated with the LSRP factors. Assessment, 15(4), 
450-463.

Miller, J. D., Lyman, D. R., Widiger, T. A., \& Leukefeld, C. (2001). Personality disorders as extreme variants of common personality dimensions: Can the five factor model adequately represent psychopathy?. Journal of personality, 69(2), 253-276.

Minhat, H. S., Hamizah, S., \& Nor Afiah, Z. (2015). A qualitative study on ageing related anxiety among middle aged women in Malaysia. Malaysian Journal of Public Health Medicine, 15(2), 1-7.

Olanrewaju, A. S., Dominic, O. B., Julius, O. A., \& Funmilola, A. (2014). Influence of psychopathy and cultic disposition on attitude toward violence among students of tertiary institutions in Ekiti state. Asian Social Science, 10(17), 258-264. https://doi.org/10.5539/ass.v10n17p258

Pallant, J. (2007). SPSS survival manual. Buckingham: Open University Press.

Ross, S. R., Lutz, C. J., \& Bailley, S. E. (2004). Psychopathy and the five factor model in a noninstitutionalized sample: A domain and facet level analysis. Journal of Psychopathology and Behavioral Assessment, 26(4), 213-223.

Savard, C., Lussier, Y., Sabourin. S., \& Brassard, A. (2005). French-Canadian validation of the Levenson self-report psychophathy scale. Canadian Psychological Association, 1-4.

Stevens, J. P. (1992). Applied multivariate statistics for the social sciences. Hillsdale, NJ: Erlbaum.

Tabachnick, B. G., \& Fidell, L. S. (2007). Using multivariate statistics. Boston: Allyn \& Bacon.

Tsuey Chong, S., Mohamad, M. S., \& Er, A. C. (2013). The mental health development in Malaysia: History, current issue and future development. Asian Social Science, 9(6), 1-8. https://doi.org/10.5539/ass.v9n6p1

Vally, Z., \& Abrahams, L. (2016). The Effectiveness of Peer-Delivered Services in the Management of Mental Health Conditions: a Meta-Analysis of Studies from Low- and Middle-Income Countries. International Journal for the Advancement of Counselling, 38(4), 330-344. https://doi.org/10.1007/s10447-016-9275-6

Vincent, N. A. (Ed.). (2013). Neuroscience and legal responsibility. Oxford University Press.

Walters, G. D., Brinkley, C. A., Magaletta, P. R., \& Diamond, P. M. (2008). Taxometric analysis of the Levenson self-report psychopathy scale. Journal of Personality Assessment, 90(5), 491-498.

Yamawaki, N., Riley, C., Sato, T., \& Omori, M. (2015). Beliefs about causes of and risk factors for mental disorders: A comparison of Japanese and American college students. Asian Social Science, 11(15), 197-203. https://doi.org/10.5539/ass.v11n15p197

Zuliza, M. S., Irniza, R., \& Emilia, Z. A. (2017). Sick building syndrome and mental health among university laboratory staffs. Malaysian Journal of Public Health Medicine, 2017(Special issue1), 133-139.

\section{Copyrights}

Copyright for this article is retained by the author(s), with first publication rights granted to the journal.

This is an open-access article distributed under the terms and conditions of the Creative Commons Attribution license (http://creativecommons.org/licenses/by/4.0/). 